\title{
Análise Sensorial De Alimentos: Aplicações Recentes
}

Bruna Nichelle Lucas, Flávia Michelon Dalla Nora

https://doi.org/10.4322/mp.978-65-994457-0-5.c5

\section{Resumo}

O desenvolvimento de produtos alimentícios é feito sempre buscando a obtenção de alimentos seguros, sendo que avaliações químicas, físicas e microbiológicas são empregadas para este fim e consistem em análises de extrema importância, pois visam garantir a segurança e qualidade dos produtos que são oferecidos para população. No entanto, mesmo que todas as características em relação a segurança dos alimentos estejam adequadas, muitas vezes esses produtos não estão sensorialmente adequados do ponto de vista do consumidor. Desta forma, a Análise Sensorial de Alimentos é uma peça chave dentro das indústrias de alimentos, pois avaliar se aquele produto que está sendo desenvolvido ou até mesmo sofrendo um processo de alteração no seu processo produtivo está de acordo com as exigências do mercado consumidor é peça chave para o sucesso de mercado. Como vimos nos capítulos anteriores, diversos testes clássicos podem ser empregados com o objetivo de avaliar a qualidade sensorial dos alimentos e garantir que o produto que está chegando até a mesa do consumidor satisfaça suas exigências. Sendo assim, este último capítulo do livro de "Análise Sensorial de Alimentos - Métodos Clássicos" busca trazer aplicações recentes no campo de aplicação de testes sensoriais com o objetivo principal de garantir a qualidade sensorial dos alimentos que estão em etapa de pesquisa e desenvolvimento. Neste sentido, o presente capítulo busca descrever os principais testes aplicados recentemente na área de análise sensorial de alimentos, suas principais características e resultados obtidos.

Palavras-chave: desenvolvimento de novos produtos, indústria de alimentos, qualidade sensorial, testes sensoriais.

\section{Introdução}

A qualidade dos alimentos pode ser medida por vários aspectos, dentre os quais pode-se citar a qualidade microbiológica, físico-química, nutricional e, 
por fim, a qualidade sensorial. Desta forma, a qualidade sensorial de diversos produtos é de extrema importância, haja visto que é o aspecto fundamental para que os consumidores busquem por aquele produto [1]. Como pode ser observado nos capítulos anteriores, diversos métodos estão disponíveis para a avaliação sensorial principalmente de alimentos. Estes métodos são amplamente empregados e de grande conhecimento dos profissionais que atuam na pesquisa e desenvolvimento sejam de novos produtos ou até mesmo para avaliar a influência da troca de matérias-primas ou até mesmo alteração dos métodos de processamento [1-3]. Neste sentido, este capítulo tem por objetivo principal agrupar alguns trabalhos recentes em que a análise sensorial de alimentos foi aplicada, buscando relatar peculiaridades, principalmente dos métodos clássicos e suas possibilidades.

\section{Pesquisas recentes no campo de Análise Sensorial de Alimentos}

A avaliação de atributos ou até mesmo de um produto como um todo é tradicionalmente realizada empregando testes sensoriais clássicos [1]. Neste sentido, observou-se nos capítulos anteriores as especificidades e generalidades de cada grupo de testes, bem como o objetivo que busca-se quando um determinado teste é aplicado.

\subsection{Testes afetivos de aceitação}

Um dos principais grupos de testes sensoriais são os testes afetivos, os quais são considerados testes que permitem a obtenção de respostas em relação a opinião dos julgadores frente a um determinado produto. Esta classe de testes é subdividida em testes de preferência e aceitação, os quais distinguem-se entre si principalmente em relação ao objetivo de cada um [1]. Este grupo de testes é considerado o mais simples no âmbito de análise sensorial e, normalmente é empregado para avaliação de mercado e da opinião dos consumidores. Desta forma, para a aplicação destes testes, preferencialmente julgadores não treinados devem ser recrutados [3].

Os testes de aceitação são aplicados com o objetivo de avaliar a aceitação de um certo produto pelos julgadores, sendo que durante a aplicação destes testes é solicitado aos julgadores que indiquem o quanto gostaram ou desgostaram do respectivo produto e não qual é o seu preferido [1, 2]. Além 
disso, estes testes permitem que sejam obtidas informações a respeito da opinião dos julgadores sobre um determinado produto. São testes aplicados normalmente no desenvolvimento de novos produtos, otimização de processos ou alteração de produtos e até mesmo para avaliação de um mercado em potencial para um dado alimento [3]. A aplicação de testes de aceitação pode ser feita para avaliar um único atributo ou para avaliar um produto de forma global quanto a opinião do julgador. O procedimento de aplicação deste teste, considerando suas especificidades, apresentação de amostras e tratamento estatístico dos dados obtidos é mencionado na íntegra no Capítulo 3 deste livro.

Neste contexto, diversos trabalhos vêm sendo desenvolvidos recentemente empregando testes afetivos de aceitação, dentre os quais, destacam-se o uso de testes empregando escalas. Os testes empregando escalas são conduzidos através do uso de escalas com 5, 7 e 9 pontos, sendo a última a mais comumente empregada.

Neste contexto, em um trabalho recente empregando uma escala de 7 pontos Hedhili et al. [4] avaliaram a aceitação de biscoitos suplementados com folhas secas de Moringa oleiferaé, a qual é caracterizada por apresentar composição rica em aminoácidos e por apresentar grande potencial antioxidante [4]. Neste estudo, um painel constituído por 91 julgadores avaliou amostras deste produto em desenvolvimento em relação ao atributo sabor, expressando sua opinião através da escala numérica [4]. Além disso, neste mesmo estudo os julgadores avaliaram uma série de 4 formulações de biscoitos com quantidades crescentes do material vegetal quanto a aceitação em relação aos atributos aparência, odor, sabor e textura, empregando para isso uma escala hedônica de 7 pontos [4]. Após a avaliação estatística empregando uma análise de componentes principais foi possível observar que a textura e a cor verde dos biscoitos foram a condição em que mais interferiram na aceitação das amostras [4]. Além disso, os biscoito com suplementação de Moringa oleiferaé obtiveram os menores escores de aceitação por parte dos julgadores, sendo que o biscoito sem a adição do material vegetal foi o mais preferido pelos julgadores [4].

Orqueda et al. [5] realizaram um estudo bastante similar para avaliar a aceitação de polpa de Solanum betaceum Cav. com diferentes cores de casca 
e em diferentes tempos de armazenamento sob congelamento [5]. Um painel não treinado constituído por 80 julgadores avaliaram amostras de polpa em relação aos atributos sabor geral, cor, aparência, aroma, sabor global, sabor ácido, textura e gosto residual utilizando uma escala hedônica de 7 pontos [5]. De acordo com os autores, todas as formulações avaliadas pelos julgadores obtiveram índica de aceitação maior ou igual a 70\%, indicando uma boa aceitabilidade das amostras avaliadas [5]. De acordo com os dados deste estudo, as amostras que não continham sementes apresentaram aceitabilidade maior quando comparada as que continham sementes [5]. Vale salientar ainda, que de acordo com os resultados obtidos, este fruto, considerado nativo, apresenta um elevado potencial para aplicação, pois mesmo em tempos prolongados de congelamento apresentaram adequada qualidade microbiológica, físico química e sensorial [5].

Em outro estudo conduzido no último ano, pesquisadores avaliaram através de uma escala de 9 pontos a influência do uso de desidroacetato de sódio sob a vida de prateleira de macarrão úmido armazenado a temperatura de refrigeração e sob temperatura ambiente [6]. Neste estudo, foi feita uma abordagem não tradicionalmente conduzida com testes de aceitação, tendo em vista que foi empregado um painel composto por 9 indivíduos que julgaram as amostras de estudo e uma amostra controle em relação ao odor e aceitabilidade geral, na qual a nota 1 indicava qualidade extremamente baixa e 9 alta qualidade [6]. De acordo com os autores, através de análises físicoquímicas, microbiológicas e sensoriais foi possível inferir que o uso de desidroacetato de sódio tanto para amostras armazenadas a temperatura ambiente quanto sob refrigeração permitiu um maior tempo de prateleira [6]. No que diz respeito aos atributos sensoriais, as amostras que foram tratadas com desidroacetato de sódio mantiveram por mais tempo as características sensoriais do produto sob os dois modos de armazenamento estudados [6].

O óleo de insetos vem sendo utilizados em produtos alimentícios dos consumidores ocidentais, pois permitem a substituição parcial de manteiga em produtos de panificação [7]. Neste contexto, Tzompa-Sosa et al. [7], avaliaram o efeito da desodorização na avaliação sensorial, pela substituição de óleo vegetal por óleo de inseto em produtos alimentícios. O presente estudo propôs reduzir sabores indesejáveis do óleo de inseto e promover o aumento da 
substituição de óleo em produtos alimentícios. Para isso, utilizou-se o feito desodorizante do óleo de larva de farinha amarela (Tenebrio molitor) na substituição parcial e total do óleo vegetal em biscoitos e húmus [7].

A avaliação sensorial foi realizada utilizando três procedimentos, a avaliação de gosto geral (escala hedônica de 9 pontos), perfil sensorial e emocional (CATA) e intenção de compra. Cada julgador avaliou 5 amostras contendo, $100 \%$ de óleo vegetal, $100 \%$ de óleo de larva bruto, $100 \%$ de óleo de larva desodorizado, $50 \%$ vegetal e $50 \%$ óleo bruto de larva e $50 \%$ óleo vegetal e $50 \%$ de óleo de larva desodorizado. Os resultados apresentam uma melhor experiência alimentar para o produto que continha $100 \%$ do óleo vegetal de larva desodorizado, pois impactou o gosto geral e melhor aparência visual, porém, impactou negativamente no atributo de sabor. Desta forma, o uso do óleo vegetal de larva pode ser utilizado como substituição do óleo vegetal quando utilizado na proporção de $50 \%$ desodorizado, sem atrapalhar a aparência visual e gosto, promovendo assim o consumo de insetos nos países ocidentais [7].

O uso de escalas bilaterais para avaliar a aceitação por parte dos consumidores tem sido uma ferramenta bastante útil. Essa abordagem apesar de ser simples, permite que sejam obtidos dados relevantes para que as qualidades sensoriais buscadas pelos consumidores sejam atendidas. Neste contexto, além dos exemplos mencionados acima, recentemente este método de análise sensorial foi aplicado para diversos fins, tais como a avaliação de manteigas com presença de probióticos encapsulados [8], macarrão suplementado com proteína isolada de quinoa [9], uso de ingrediente umami como alternativa na redução de sódio e intensificador de sabor em salgadinhos extrusados de milho [10], dentre outras, as quais são mostradas na Tabela 1. 
Tabela 1. Aplicações recentes de testes afetivos de aceitação em alimentos.

\begin{tabular}{cl}
\hline Referência & \multicolumn{1}{c}{ Objetivo do estudo } \\
\hline$[4]$ & $\begin{array}{l}\text { Aceitação de biscoitos suplementados de folhas de } \\
\text { Moringa oleiferaé. }\end{array}$ \\
\hline$[5]$ & $\begin{array}{l}\text { Aceitação de polpas de Solanum betaceum Cav. com } \\
\text { diferentes cores de casca e armazenadas sob tempos } \\
\text { distintos. }\end{array}$ \\
[6] & $\begin{array}{l}\text { Avaliação da vida de prateleira e aceitabilidade de } \\
\text { macarrão com adição de desidroacetato de sódio } \\
\text { como conservante. }\end{array}$ \\
& $\begin{array}{l}\text { Aceitação de manteigas enriquecidas com probióticos } \\
\text { Lactobacillus acidophilus and Bifidobacterium bifidum } \\
\text { encapsulados. }\end{array}$ \\
Aceitabilidade de macarrão com adição de proteína \\
isolada de quinoa. \\
Aceitabilidade de snacks de milho extrusados \\
adicionados de ingrediente umami para intensificação \\
de sabor e redução do teor de sódio. \\
Avaliação da aceitabilidade do uso de baunilha na \\
composição de adoçantes para redução do teor de \\
açucares em alimentos e bebidas. \\
A11]
\end{tabular}


Como é possível observar na tabela 1, o emprego de testes de aceitação é bastante conduzido, tendo em vista que permite avaliar qual a opinião do consumidor frente a um produto. No trabalho desenvolvido por Gupta et al. [9], uma avaliação em referência a adição de proteína alternativa vegetal obtida de grãos de quinoa em macarrão foi conduzida. De acordo com os autores, a suplementação deste alimento com proteína obtida desta fonte natural foi bem aceita pelos julgadores quando quantidades de até $8 \mathrm{~g}$ a cada $100 \mathrm{~g}$ de macarrão foi feita. Em proporções maiores, a aceitabilidade por parte dos julgadores foi menor, indicando que essa quantidade seria adequada do ponto de vista sensorial. Do ponto de vista nutricional, os autores relatam que a suplementação com proteína isolada de quinoa pode ser um material promissor para a indústria de alimentos para produzir massas enriquecidas com proteínas de alta qualidade e baixo custo [9].

Considerando as demais aplicações presentes na tabela 1, é possível observar que os testes de aceitabilidade são ferramentas de extrema importância quando se quer desenvolver novos produtos ou aperfeiçoar os já existentes. Desta forma, o conhecimento da forma como estes testes devem ser conduzidos, o qual foi apresentado no Capítulo 3 constitui-se um ponto chave para profissionais atuantes na área de ciência e tecnologia de alimentos.

\subsection{Testes afetivos de preferência}

Os testes de preferência são aplicados quando deseja-se avaliar a preferência do consumidor em relação a duas ou mais amostras comparadas entre si, sem levar em conta o gosto pessoal de cada avaliador. Para obtenção de resultados confiáveis são necessárias grandes equipes de avaliadores, a fim de obter um resultado mais próximo para a população que o produto vai ser destinado. Uma abordagem detalhada do teste foi descrita no capítulo 3 deste livro.

O teste de preferência foi realizado por Cano et al. [15], através do estudo da análise sensorial e de mercado para uso de cápsulas de óleo e semente de chia, onde foi realizada uma encapsulação do óleo e posterior aplicação em leite com chocolate em pó. A análise de preferência foi aplicada a fim de obter o produto preferido para incorporar as cápsulas em farinhas, condimentos, cereais, entre outros. A formulação do produto promoveu uma 
aceitação de $46 \%$ dos consumidores, propondo um produto pouco atrativo para consumidores interessados em produtos que tragam benefícios para saúde. Vale salientar que como o óleo de semente de chia contém grandes quantidades de ômega 3, é adequado para ser protegido como ingrediente alimentar ativo por encapsulamento. De acordo com os autores, a incorporação das cápsulas de óleo de semente de chia ao leite com chocolate, em um segmento de mercado não específico, não teve o sucesso esperado. Um resultado notável foi que nenhum dos entrevistados percebeu uma textura oleosa, então a casca das cápsulas não permitiu que o óleo penetrasse e reteve o sabor de chia. Portanto, com base na análise de mercado, propõe-se a incorporação dessas cápsulas em bebidas de cereais ou de baunilha, mais atrativas aos consumidores interessados em produtos que proporcionem benefícios à saúde, obtendo maior afinidade com o sabor amargo do óleo de semente de chia. [15]

Machado [16] avaliou a incorporação de cacau na produção cervejas não pasteurizadas, através do emprego de testes afetivos de preferência e aceitação na análise sensorial. O teste afetivo de aceitação foi empregado utilizando a escala hedônica de 7 pontos, onde 1 correspondia ao termo desgostei muitíssimo, 4 ao termo indiferente e 7 gostei muitíssimo, a fim de avaliar sabor, cor, estabilidade da espuma e aparência global. Foi feita uma avaliação da preferência em relação a aparência global dos tratamentos, ordenando do mais preferido ao menos preferido. Os resultados obtidos apresentaram uma maior preferência para o tratamento que substituiu o lúpulo de amargor, sendo uma ótima opção para a adição de cacau [16].

Os testes afetivos, sejam eles de aceitação ou de preferência são testes notoriamente adequados para avaliar a opinião dos potenciais consumidores, seja através da escolha do produto preferido ou ainda pela opinião frente aos produtos. Neste sentido, estes testes são amplamente empregados em pesquisas de mercado e na avaliação de marcas concorrentes, sendo essenciais durante a pesquisa e desenvolvimento de novos produtos.

\subsection{Testes de diferença}

Outros testes sensoriais amplamente empregados na área de alimentos são os testes de diferença ou discriminativos. Estes testes são aplicados com o 
intuito de avaliar a diferença sensorial entre as amostras analisadas, utilizado para avaliações em relação a atributos específicos como sabor, cor, textura, ou ainda de forma global. São testes de fácil aplicabilidade, podendo ser aplicados no controle de qualidade de alimentos, como também no desenvolvimento de novos produtos. Além disso, esta classe de testes destaca-se por serem consideradas ferramentas importantes empregadas durante a seleção e 0 treinamento de painéis treinados. Neste livro, uma abordagem mais detalhada destes testes foi feita no capítulo 3 , no qual as especificidades de cada teste, sua metodologia de aplicação e avaliação estatística está descrita.

Recentemente, há diversas pesquisas aplicando os testes de diferença, dentre as quais destacam-se a aplicação para comparar o uso de substâncias com ação de intensificador de sabor, percepção do sabor e textura de biscoitos com redução do teor de sal e avaliação sensorial de alimentos armazenados sob diferentes condições. Na tabela 2 são mostrados alguns exemplos de aplicações de testes discriminativos recentes para a avaliação de alimentos.

Tabela 2. Aplicações recentes de testes de diferença em alimentos.

\section{Referência}

[17]

\section{Objetivo do estudo}

Comparação de intensificador de sabor natural ao comercial

Avaliar a diferença de sabor e textura de biscoitos doces após uma redução de sal

Avaliar o impacto do congelamento temporário em produtos de panificação

Avaliar a diferença de mortadelas contendo óleo essencial

De acordo com a tabela 2, Wijayasekara \& Wansapala [17] empregaram um teste de diferença para comparar o uso de um intensificador de sabor 
usando ingredientes naturais locais em substituição do glutamato monossódico. Neste estudo, foram avaliadas diferentes formulações de uma mistura seca como intensificador de sabor contendo, cogumelo, tomate, cenoura, alho e sal, afim de descobrir qual o produto mais preferido pelos julgadores. Os autores selecionaram a formulação que obteve maior preferência pelos julgadores e não comparou com a formulação original contendo glutamato monossódico, comercialmente disponível como ajinomoto. Foram feitas avaliações empregando um teste de diferença para avaliar os atributos de sensação na boca, cor, sabor, odor, gosto residual e aceitabilidade geral. Os autores avaliaram os dados obtidos estatisticamente através do teste Mann-Whitney ao nível de significância de 0.005 [17].

De acordo com os dados obtidos, foi possível observar que os resultados revelaram uma média mais alta em relação a cor e gosto residual para a amostra original contendo o glutamato monossódico de sódio em relação a amostra teste. Contudo, o produto no qual foram utilizadas outras especiarias apresentou uma média maior, em relação ao sabor. No que diz respeito aos atributos odor, sensação na boca e aceitabilidade geral, os resultados proferidos pelos julgadores indicaram que não houve diferença significativa entre as amostras avaliadas. Portanto, pode-se observar que a fórmula selecionada não mostrou-se diferente, ou seja, foi considerada semelhante a amostra empregando o intensificador de sabor, o que reflete diretamente na possibilidade de propor este novo produto, que apresenta menores efeitos adversos e toxicológicos ao consumidor. [17]

Em outro estudo bastante similar, pesquisadores avaliaram a diferença de sabor e textura de biscoitos doces após uma redução de sal [18]. Este trabalho foi feito com o objetivo de verificar qual o impacto da redução do sal em biscoitos doces, tendo em vista que este sal é considerado como "escondido". Para isso, foi aplicado um teste triangular contendo 108 julgadores não treinados, com idades entre 18 e 70 anos. Através do perfil sensorial e análises físico-químicas pode-se observar uma diferença significava no sabor doce e textura frágil dos biscoitos com redução de sal de $33 \%$. O painel treinado conseguiu perceber as diferenças, no entanto, não conseguiu relacionar essa diferença com a diminuição do teor de sal nas formulações. Desta forma, o presente estudo revelou pela primeira vez que mesmo não 
sendo perceptível, o sal apresenta um papel importante na formação da estrutura do biscoito doce e na disponibilidade do sabor no que diz respeito ao aspecto sensorial. Sendo assim, este estudo demonstra que é necessária uma investigação que promova a redução de sal e que preserve as propriedades sensoriais dos biscoitos doces e que tenha boa aceitabilidade pelos consumidores [18].

Pinelli et al. [20] propôs como a aplicação de nanoemulsões de óleo essencial para o controle de esporos de Clostridium em produto cárneo cozido. Neste estudo foi feita a avaliação da atividade antimicrobiana, análises físicoquímicas e sensoriais de mortadela contendo nanoemulsões de óleo essencial. No que diz respeito a análise sensorial foi aplicado um teste de diferença, empregando um grupo focal com julgadores não treinados, os quais avaliaram aroma, aparência, sabor e textura, como também a diferença da amostra controle, através de escala de 6 pontos, onde 0 indicava nenhuma diferença e 6, grande diferença. A proposta de aplicação de nanoemulsões de óleo essencial apresentou resultados promissores em relação a atividade antimicrobiana, porém em relação aos efeitos sensoriais apresentaram resultados insatisfatórios para as formulações usadas. [20]

Recentemente, Bockstaele et al. [19] avaliaram através de um teste discriminativo o impacto do armazenamento temporário congelado na segurança e qualidade de quatro produtos típicos na panificação belga. Um teste triangular foi aplicado com o objetivo de verificar a diferença entre os produtos de panificação não congelados e congelados/descongelados durante seu armazenamento. Os pesquisadores observaram que o armazenamento temporário de produtos de panificação congelados, como pão integral, sanduíches, pão de ló e torta de cereja, não reduziu a qualidade microbiológica, como também obteve uma alta aceitabilidade dos consumidores. Portanto, o congelamento temporário não reduziu a qualidade do ponto de vista do consumidor e do produto final [19].

\subsection{Testes descritivos}

Os métodos descritivos têm por objetivo principal descrever e quantificar as características de cada amostra, tais como a aparência, aroma, sabor e textura, como também, avaliar a intensidade de cada característica, através de 
uma equipe de julgadores treinados [21]. Nos últimos anos, métodos de análise sensorial descritivos vêm sendo bastante utilizados no controle de qualidade de alimentos, pois proporciona informações detalhadas e importantes dos produtos e do consumidor. Além disso, os métodos descritivos permitem um mapeamento geral sobre o produto sob avaliação, indicando de forma completa quais são os atributos que precisam ser melhorados para a obtenção de um produto que satisfaça as necessidades dos consumidores. Atualmente é a classe de testes sensoriais mais aplicada principalmente por requerer pequenas equipes de julgadores treinados, constituindo-se como uma ferramenta de grande valia dentro de indústrias de alimentos.

Vários estudos de pesquisa e desenvolvimento também empregam essas metodologias para avaliação sensorial de seus produtos, como pode ser visto no trabalho conduzido por Laaksonen et al. [22]. Neste estudo foi feita a investigação do impacto da fermentação do ácido lático na qualidade sensorial e química de misturas lácteas preparadas a partir de sementes de Lupinus angustifolius $L A$ avaliação da qualidade sensorial dos produtos fermentados $e$ não fermentados foi realizada utilizando análise descritiva genérica e testes afetivos. Para isso, foram utilizados 17 julgadores treinados, para que avaliassem os atributos de aparência, odor, sabor e textura das amostras. A fermentação láctica afetou significativamente a qualidade sensorial dos produtos, a qual causou um aumento do teor de acidez e do odor de "vinagre" e reduziu o odor e sabor de "feijão", como também, apresentou sabor desagradável. Com a aplicação deste teste é possível observar que pequenas características são avaliadas e, neste caso, o presente estudo relatou a importância de selecionar cepas de bactérias de fermentação de ácido lático e a necessidade de otimização do processo, afim de obter produtos com características sensoriais que reflitam em maior aceitação pelos consumidores. [22]

Ainda aplicando testes descritivos, Li et al. [23], avaliaram o efeito de extrato aquoso de escamas de peixe no preparo de géis alimentares. Os atributos sensoriais dos géis incluindo odor, cor, sabor e elasticidade foram determinados utilizando Análise Descritiva Quantitativa, a ADQ. Foi criando um painel constituído por 10 julgadores treinados e uma escala de 0 a 10 foi aplicada para descrever a intensidade dos atributos sensoriais. Os atributos 
avaliados foram: cheiro ou odor (de $10=$ odor desejável a $0=$ odor inaceitável), cor (de $10=$ transparente e uniforme a $0=$ opaco), sabor (de $10=$ fino a $0=$ áspero) e elasticidade (de 10 = elástico a 0 = não elástico). De acordo com os autores, foi possível observar variações significativas em relação ao odor, o qual em altas concentrações do extrato de peixe causou um cheiro forte de peixe nos géis, tornando o produto inaceitável aos consumidores, porém adicionados de cloreto de sódio e sacarose apresentaram, melhores características na cor e sabor, refletindo em um produto com potencial maior aceitação [23]

Atributos de sabor de espécies Pinaceae, foram investigados por Valerón et al. [24]. Neste trabalho foram escolhidos 33 descritores diferentes para análise sensorial com o intuito de relacionar com as diferentes amostras de Pinaceae. A pesquisa foi realizada através do método estatístico Check-AllThat-Apply (CATA), no qual os descritores ácido, cor escura e clara, sabor intenso, sabor de toranja e sabor cítrico foram avaliados. De acordo com os autores, todos os descritores apresentaram diferença significativa entre as amostras. A amostra Abies grandis apresentou sabor cítrico, intenso e de toranja, em contrapartida a amostra a Pseudotsuga menziesii apresentou cor escura e amargor e a amostra de Picea abies está relacionada à cor clara e doçura. A partir destes resultados, foi elaborado um sorvete para avaliar a aplicabilidade das espécies como tempero culinário e, tendo em vista que foi observado que as espécies apresentaram sabor específico, mas que não afetaram significativamente o gosto dos consumidores, foi possível concluir que espécies de Pinaceae podem ser aplicadas como novos ingredientes gastronômicos [24].

Buldo et al. [25] analisaram o papel das culturas starters nas propriedades lubrificantes e palatáveis de diversos produtos lácteos fermentados. Para avaliar as características de ingestão oral e sensação na boca foi aplicado análise sensorial descritiva com painelistas treinados. Neste estudo, os julgadores observaram e avaliaram os atributos de textura visual, através de características tais como sinérese, viscosidade, firmeza de gel e grãos visuais. Foi feita também a avaliação da textura na boca, através dos seguintes parâmetros: revestimento bucal, espessura na boca, adstringência, gorduroso, arenoso, granuloso, viscoso. A intensidade dos atributos sensoriais 
foi avaliada em escala "não estruturada" e "estruturada". De acordo com os resultados obtidos, ficou evidente que as culturas starters promoveram uma melhoria da textura visual e da sensação na boca, como também promoveram o aumento da sensação de gordura, reduzindo a granulação. [25]

Santos \& Capriles [26], avaliaram o efeito da substituição da farinha de arroz por farinha de grão de bico e combinações com psyllium sobre os perfis de textura de pão sem glúten durante o armazenamento. Foram realizadas análises físico-químicas, termodinâmicas, analise do perfil de textura, aceitabilidade e gosto geral, através da análise descritiva CATA. O estudo considerou a aceitabilidade sensorial de textura e gosto geral, descritos como: envelhecido, úmido, macio, seco, elástico e quebradiço. Os dados obtidos permitiram observar que a substituição da farinha de arroz pela de grão de bico permitiu uma redução no endurecimento do pão o que favoreceu uma melhor qualidade e aceitação, o qual foi descrito como macio e fresco durante os 7 dias de armazenamento. Portanto, mostra-se um estudo promissor na avaliação da qualidade e aceitabilidade do novo produto, podendo ser útil para pesquisar futuras [26].

No trabalho desenvolvido por Nguyen et al. [27], foi feita a identificação dos impulsionadores temporais de gosto e saciedade com base em descrições sensoriais temporais e avaliações do consumido. Essas informações foram relacionadas quanto às expectativas do consumidor, como gosto e saciedade. Para isso chegar nesta conclusão, foram utilizadas amostras de iogurte com composição idêntica, variando apenas as propriedades de textura. Para descrever os perfis dinâmicos a análise Temporal-Check-All-That-Apply (TCATA) foi empregada juntamente coma avaliação da preferência de cada iogurte. $O$ estudo permitiu encontrar diferenças significativas entre os atributos avaliados, apresentando um método adequado para avaliar o gosto e saciedade durante o consumo dos alimentos pelos consumidores de diferentes comportamentos e preferências alimentares [27].

Os atributos sensoriais de intensidade foram avaliados por Choi \& Lee [28], através do estudo dos perfis voláteis e sensoriais de diferentes cultivares de arroz preto (Oryza sativa L.) com graus de moagem distintos. O estudo foi conduzido pela aplicação de análises descritivas com painelistas treinados, os quais classificaram as amostras de acordo com as intensidades dos descritores 
sensoriais de aroma (esgoto, floral, grãos, mofado, pipoca, milho, gramíneo, laticínios, doce e fumaça), gosto (doce, azedo e amargo) e textura (adstringente). Foi aplicada uma escala de 0 a 15, onde pontuação "zero" indicava baixa intensidade e pontuação 15 alta intensidade dos atributos. De acordo com os autores, a análise descritiva apresentou diferenças significativas em 13 descritores e, após o processo de moagem, as intensidades dos atributos sensoriais diminuíram. Porém, para os descritores sensoriais floral, aroma doce e sabor doce aumentaram a intensidade independente do cultivar. Para a análise de regressão de mínimos quadrados foi identificado aroma de pipoca e defumado do arroz preto cozido, tornando uma fonte inovadora de aditivo alimentar para a indústria alimentícia devido o aroma de fumaça [28].

Neste contexto, além dos trabalhos exemplificados acima há outros trabalhos recentes aplicando os testes descritivos, como a identificação de impulsionadores temporais de gosto e saciedade com base em descrições temporais e avaliação do consumidor, avaliação da textura de pão sem glúten durante o armazenamento, avaliação sensorial de smoothies à base de espinheiro-mar, dentre outros, os quais são mostrados na tabela 3.

Tabela 3. Aplicações recentes de testes descritivos em alimentos.

\section{Referência}

[22]

[23]

[28]

\section{Objetivo do estudo}

Avaliar o impacto da fermentação do ácido lático na qualidade sensorial e química de misturas lácteas preparadas a partir de sementes de Lupinus angustifolius $L$.

Avaliar o efeito de extrato aquoso de escamas de peixe no preparo de géis alimentares

Avaliar atributos de sabor de espécies Pinaceae

Avaliar o papel das culturas starters nas propriedades lubrificantes e palatáveis de diversos produtos lácteos fermentados

Avaliar perfis voláteis e sensoriais de diferentes cultivares de arroz preto (Oryza sativa L.) 
[7]

Avaliação sensorial do feito da desodorização pela substituição de óleo vegetal por óleo de inseto em alimentos.

[29] Compreender a percepção sensorial e preferências do consumidor em relação ao consumo de alimentos semi-sólidos.

[30] Avaliar a relação entre as características sensoriais dos produtos comerciais de iogurte e sua carga microbiana.

Avaliar o emprego de concentrado de farelo de Brassica juncea para o preparo de pão melhorado funcionalmente.

Avaliar a lubricidade da saliva e a percepção oral de bebidas lácteas.

Avaliar o efeito de leveduras nativas Saccharomyces e não Saccharomyces em compostos de aroma de cerveja

Avaliar a relação entre os parâmetros termomecânicos da massa e as propriedades físicas e sensoriais da textura do pão sem glúten durante o armazenamento.

Identificar impulsionadores temporais de gosto e saciedade com base em descrições sensoriais temporais e avaliações do consumidor.

Através da análise dos trabalhos apresentados, é possível observar a importância do emprego da análise sensorial no controle de qualidade de alimentos, como também no desenvolvimento de novos produtos, pois podemos ter uma análise detalhada de diversos fatores como seleção de matéria-prima, efeito de processamento, textura, sabor, estabilidade de armazenamento e o mais importante a reação e preferência dos consumidos. Nas tabelas 1, 2 e 3 são mostrados os principais trabalhos desenvolvidos no campo de análise sensorial no primeiro quadrimestre de 2021, o que permite 
inferir que a Análise Sensorial como um todo é um campo vasto de conhecimento e que requer profissionais em constante aperfeiçoamento.

Um ponto que não foi abordado neste livro de "Análise Sensorial de Alimentos -Métodos Clássicos" é em relação ao uso de novas tecnologias empregadas no campo de Análise Sensorial. Dentre essas novas abordagens, métodos empregando equipamentos como nariz eletrônico, língua eletrônica, dentre outros são novas tendências no campo desta área. No entanto, mesmo empregando equipamentos sofisticados como estes, a obtenção da real opinião dos consumidores não pode ser substituída, o que torna o uso de métodos clássicos como as ferramentas mais adequadas para estas avaliações.

Ademais, o uso da neurociência aliada a Análise Sensorial é uma abordagem ainda em estágios iniciais, constituindo-se como uma ferramenta promissora dentro desta área, tendo em vista que reflete nas sensações cerebrais que acontecem durante as avaliações sensoriais. O uso desta abordagem revolucionária consegue captar desde estímulos nervosos não perceptíveis pelos julgadores como também expressões faciais dependendo da amostra que está sendo avaliada. Essa abordagem constitui-se como uma ferramenta promissora, mas ainda distante da realidade de pequenos grupos de estudo.

\section{Considerações finais}

A qualidade sensorial na indústria de alimentos, tem se tornado cada vez mais importante, pois analisa e interpreta informações fundamentais no desenvolvimento de novos produtos. Através desta ciência, é avaliada compreensão dos consumidores frente aos atributos sensoriais, características do produto e intenção de compra, baseadas nos cinco sentidos humanos.

Desta forma, podemos observar diversas aplicabilidades dos métodos apresentados neste livro na avaliação da qualidade sensorial de novos produtos. Embora técnicas clássicas ainda são bastante utilizadas como os testes de aceitação, podem ser inadequadas para uma descrição completa da qualidade sensorial de produtos alimentícios. Neste contexto, alguns testes como CATA e ADQ, são testes que avaliam de forma mais detalhada cada característica dos produtos, obtendo uma informação descritiva sensorial completa. Sendo assim, este último capítulo buscou trazer observações 
importantes na compreensão das análises de produtos alimentares e consumidores, através da abordagem de assuntos relevantes na escolha das técnicas, como também uma maior profundidade nas informações das técnicas existentes.

\section{Referências}

[1] Dutcosky S. D. Análise sensorial de alimentos: Editora Champagnat; 2007.

[2] Lawless H. T., Heymann H. Sensory Evaluation of Food: Principles and Practices: Springer; 1999.

[3] Stone H. Sensory evaluation practices. 3rd ed.. ed. Sidel JL, editor. Amsterdam Boston : Elsevier Academic Press; 2004.

[4] Hedhili A., Lubbers S., Bou-Maroun E., Griffon F., Akinyemi B. E., Husson F., Valentin D. Moringa Oleifera supplemented biscuits: Nutritional values and consumer segmentation. South African Journal of Botany. 2021;138:406 14. https://doi.org/10.1016/j.sajb.2021.01.017.

[5] Orqueda M. E., Torres S., Verón H., Pérez J., Rodriguez F., Zampini C., Isla M. I. Physicochemical, microbiological, functional and sensory properties of frozen pulp of orange and orange-red chilto (Solanum betaceum Cav.) fruits. Scientia Horticulturae. 2021;

276:109736. https://doi.org/10.1016/j.scienta.2020.109736.

[6] Yang S., Shan C.-S., Xu Y.-Q., Jin L., Chen Z.-G. Dissimilarity in sensory attributes, shelf life and spoilage bacterial and fungal microbiota of industrialscale wet starch noodles induced by different preservatives and temperature. Food Research International. 2021; 140:109980. https://doi.org/10.1016/j.foodres.2020.109980.

[7] Tzompa-Sosa D. A., Dewettinck K., Gellynck X., Schouteten J. J. Replacing vegetable oil by insect oil in food products: Effect of deodorization on the sensory evaluation. Food Research International. 2021; 141:110140. https://doi.org/10.1016/j.foodres.2021.110140.

[8] Naissinger da Silva M., Tagliapietra B. L., Richards N. S. P. d. S. Encapsulation, storage viability, and consumer acceptance of probiotic butter. LWT. 2021;139:110536. https://doi.org/10.1016/j.Iwt.2020.110536.

[9] Gupta A., Sharma S., Reddy Surasani V. K. Quinoa protein isolate supplemented pasta: Nutritional, physical, textural and morphological 
characterization.

LWT.

2021;

135:110045.

https://doi.org/10.1016/j.lwt.2020.110045.

[10] Xue S., Setyabrata D., Bonham C. C., Kim Y. H. B. Evaluation of functional and chemical properties of crust from dry-aged beef loins as a novel food ingredient. Meat $\quad$ Science. $2021 ;$ 173:108403. https://doi.org/10.1016/j.meatsci.2020.108403.

[11] Bertelsen A. S., Zeng Y., Mielby L. A., Sun Y.-X., Byrne D. V., Kidmose U. Cross-modal Effect of Vanilla Aroma on Sweetness of Different Sweeteners among Chinese and Danish Consumers. Food Quality and Preference. 2021;87:104036. https://doi.org/10.1016/j.foodqual.2020.104036.

[12] Manzoor M., Sharma V., Singh D., Sohal J. S., Aseri G. K., Khare N., Vij S., Saroop J., Sharma D. Functional Pediococcus acidilactici BC1 for the revitalization of ethnic black carrot kanji of indian subcontinent. Biocatalysis and $\begin{array}{lll}\text { Agricultural } \quad \text { Biotechnology. } & \text { 31:101921. }\end{array}$ https://doi.org/10.1016/j.bcab.2021.101921.

[13] Jo D.-M., Park S. K., Khan F., Kang M. G., Lee J. H., Kim Y.-M. An approach to extend the shelf life of ribbonfish fillet using lactic acid bacteria cellfree culture supernatant. Food Control. 2021; 123:107731. https://doi.org/10.1016/j.foodcont.2020.107731.

[14] Oliveira A. A. A., Andrade A. C., Bastos S. C., Condino J. P. F., Curzi Júnior A., Pinheiro A. C. M. Use of strawberry and vanilla natural flavors for sugar reduction: A dynamic sensory study with yogurt. Food Research International. 2021; 139:109972. https://doi.org/10.1016/j.foodres.2020.109972. [15] Amaya Cano J. S., Segura Pacheco S., Salcedo Galán F., Arenas Bustos I., Rincón Durán C., Hernández Carrión M. Formulation of a responsive in vitro digestion wall material, sensory and market analyses for chia seed oil capsules. Journal of Food Engineering. 2021; 296:110460. https://doi.org/10.1016/j.jfoodeng.2020.110460.

[16] Machado E. R. Desenvolvimento e caracterização de cerveja artesanal com adição de cacau. Dissertação de Mestrado. Universidade Federal de Santa Maria; 2017.

[17] Wijayasekara K. N., Wansapala J. Comparison of a flavor enhancer made with locally available ingredients against commercially available Mono Sodium 
Glutamate. International Journal of Gastronomy and Food Science. 2021; 23:100286. https://doi.org/10.1016/j.ijgfs.2020.100286.

[18] Ayed C., Lim M., Nawaz K., Macnaughtan W., Sturrock C. J., Hill S. E., Linforth R., Fisk I. D. The role of sodium chloride in the sensory and physicochemical properties of sweet biscuits. Food Chemistry: X. 2021; 9:100115. https://doi.org/10.1016/j.fochx.2021.100115.

[19] Van Bockstaele F., Debonne E., De Leyn I., Wagemans K., Eeckhout M. Impact of temporary frozen storage on the safety and quality of four typical Belgian bakery products. LWT. 2021; 137:110454. https://doi.org/10.1016/j.lwt.2020.110454.

[20] Pinelli J. J., Helena de Abreu Martins H., Guimarães A. S., Isidoro S. R., Gonçalves M. C., Junqueira de Moraes T. S., Ramos E. M., Piccoli R. H. Essential oil nanoemulsions for the control of Clostridium sporogenes in cooked meat product: An alternative? LWT. 2021:111123. https://doi.org/10.1016/j.lwt.2021.111123.

[21] Richter V. B., de Almeida T. C. A., Prudencio S. H., de Toledo Benassi M. Proposing a ranking descriptive sensory method. Food Quality and Preference. 2010; 21(6):611-20. https://doi.org/10.1016/j.foodqual.2010.03.011.

[22] Laaksonen O., Kahala M., Marsol-Vall A., Blasco L., Järvenpää E., Rosenvald S., Virtanen M., Tarvainen M., Yang B. Impact of lactic acid fermentation on sensory and chemical quality of dairy analogues prepared from lupine (Lupinus angustifolius L.) seeds. Food Chemistry. 2021; 346:128852. https://doi.org/10.1016/j.foodchem.2020.128852.

[23] Li J., Yu X., Tang W., Wan C., Lu Y., Dong N., Chen Z., Lei Z., Ren T., Wang Z., Liu J. Characterization of food gels prepared from the water extract of fish (Cyprinus carpio L.) scales: From molecular components to sensory $\begin{array}{llll}\text { attributes. } & \text { Food } \quad \text { Hydrocolloids. 2021; 112:106263. }\end{array}$ https://doi.org/10.1016/j.foodhyd.2020.106263.

[24] Valerón N. R., Vásquez D. P., Munk R. The Pinaceae species, flavor attributes for new culinary spices. International Journal of Gastronomy and Food Science. 2021; 23:100306. https://doi.org/10.1016/j.ijgfs.2021.100306. [25] Buldo P., Sokolowsky M., Hoegholm T. The role of starter cultures on oral processing properties of different fermented milk products. Food Hydrocolloids. 2021; 114:106571. https://doi.org/10.1016/j.foodhyd.2020.106571. 
[26] Santos F. G., Capriles V. D. Relationships between dough thermomechanical parameters and physical and sensory properties of glutenfree bread texture during storage. LWT. 2021; 139:110577. https://doi.org/10.1016/j.lwt.2020.110577.

[27] Nguyen Q. C., Varela P. Identifying temporal drivers of liking and satiation based on temporal sensory descriptions and consumer ratings. Food Quality and Preference. 2021;

89:104143. https://doi.org/10.1016/j.foodqual.2020.104143.

[28] Choi S., Lee J. Volatile and sensory profiles of different black rice (Oryza sativa L.) cultivars varying in milling degree. Food Research International. 2021; 141:110150. https://doi.org/10.1016/j.foodres.2021.110150.

[29] Varela P., Mosca A. C., Nguyen Q. C., McEwan J. A., Berget I. Individual differences underlying food intake and liking in semisolid foods. Food Quality and Preference. 2021;

87:104023. https://doi.org/10.1016/j.foodqual.2020.104023.

[30] Suh S. H., Kim M. K. Microbial communities related to sensory characteristics of commercial drinkable yogurt products in Korea. Innovative Food Science \& Emerging Technologies. 2021; 67:102565. https://doi.org/10.1016/j.ifset.2020.102565.

[31] Chakraborty P., Bhattacharyya D. K., Ghosh M. Extrusion treated meal concentrates of Brassica juncea as functionally improved ingredient in protein and fiber rich breadstick preparation. LWT. 2021; 142:111039. https://doi.org/10.1016/j.lwt.2021.111039.

[32] Fan N., Shewan H. M., Smyth H. E., Yakubov G. E., Stokes J. R. Dynamic Tribology Protocol (DTP): Response of salivary pellicle to dairy protein interactions validated against sensory perception. Food Hydrocolloids. 2021; 113:106478. https://doi.org/10.1016/j.foodhyd.2020.106478.

[33] Larroque M. N., Carrau F., Fariña L., Boido E., Dellacassa E., Medina K. Effect of Saccharomyces and non-Saccharomyces native yeasts on beer aroma compounds. International Journal of Food Microbiology. 2021; 337:108953. https://doi.org/10.1016/j.ijfoodmicro.2020.108953. 


\section{Autores}

Bruna Nichelle Lucas, Flávia Michelon Dalla Nora*

Departamento de Tecnologia e Ciência dos Alimentos, Universidade Federal de Santa Maria, Av. Roraima no 1000, 97105-900, Santa Maria, Brasil.

* Autor para correspondência: flavia.nora@ufsm.br 